\title{
Introduction to the Special Issue on Student Loan Debt
}

\author{
Suzanne Bartholomae ${ }^{1}$
}

Published online: 2 February 2019

(c) Springer Science+Business Media, LLC, part of Springer Nature 2019

As the role of student loan debt in family economic behavior continues to evolve, scholarly investigations on the topic are vital. This special issue encouraged contributors to focus on the influence of student loan debt on individual and family transitions, development, and outcomes. This special issue provides readers with nine articles that illustrate the role of student loan debt in a variety of outcomes and presents a range of empirical work collectively contributing to the development of our understanding of student loan debt in the lives of individuals and families.

Montalto, Phillips, McDaniel, and Baker open the special issue by embedding student loans in a broader discussion of the multi-dimensional concept of college student financial wellness. An overview of historical and current trends in student loans is provided, and evidence from the Study on Collegiate Financial Wellness, a national data set of multiple institutions, illustrates the current state of college student financial wellness, financial stress, financial literacy, and other financial measures, including student loans.

Four of the special issue articles examine the role of student loan debt and its association with psychological outcomes. Zhan and Kim used five waves from the Transition into Adulthood Study from the Panel Study of Income Dynamics (PSID) to demonstrate the association of differential consumer debt-student loan versus credit cardon psychological distress. They found that accumulating student loan debt increased psychological distress among young adults, with higher outstanding loan balances linked to greater distress, after controlling for financial strain and other factors. Kim and Chatterjee used three waves of data from the PSID to examine the association of student loan debt with three individual outcomes-psychological problems, perceived life satisfaction, and self-reported healthcontrolling for other types of debt, assets and income, and

Suzanne Bartholomae

suzanneb@iastate.edu

1 Department of Human Development and Family Studies, Iowa State University, Ames, IA, USA other sociodemographic factors. They found negative associations among student loan debt and psychological problems and perceived life satisfaction, and self-reported health varied by socio-demographic factors, in particular race and ethnicity.

The other two articles investigating student loan debt and psychological outcomes use cross-sectional, nationally representative data from the 2015 National Financial Capability Study (NFCS) to examine consumer financial satisfaction, student loan stress, and student loan repayment behavior. Robb, Chatterjee, Porto, and Cude examined the influence of student loan debt on consumer financial satisfaction and concluded that having student loan debt had mixed associations with financial satisfaction. They found the type of loanborrowing from multiple sources (federal and private) or private lenders only (versus only borrowing federal student loans)-lowered satisfaction with previous student loan borrowing choices. Fan and Chatterjee examined the association of financial knowledge, financial socialization, attitudinal, behavioral, and sociodemographic factors with student loan repayment behavior and student loan stress. They found that previous financial education, parental financial socialization, and financial knowledge reduced the probability of respondents being late on student loan payments and worrying about student loan debt. They found interesting interaction effects between parental financial socialization and receiving formal financial education, which reduced the probability of being worried about student loan debt.

The rise in student loan debt has been an impetus for scholars to explore whether greater debt burdens are disrupting the life transitions and trajectories of young adults. Addo, Houle, and Sasser examined marital formation of young adults using two generational cohorts from the National Longitudinal Studies. The study examined the association of asset and debt holdings and relationship formation; their findings suggest that student loan debt is an economic barrier to marital transitions. Utilizing three waves of the Canadian Survey of Financial Security data, Maroto also examined the association of assets and debts, but in coresident households and with outcome measures 
of household economic security. Using propensity score matching and linear regression, she found that coresidence with, and parental support for, adult children is negatively associated with non-home assets and positively associated with debt levels among Canadian households. Further analyses suggest that these relationships stem from differences in financial assets, retirement savings, student loan debt, and credit card balances.

Two studies in the special issue use experimental procedures to test framing effects in attitudes toward student loan decisions. With samples from three Latin American countries, Caetano, Palacios, and Patrinos fielded an experimental survey to identify sources of debt aversion by measuring preferences for contracts not framed or labeled as debt (versus a loan) and the perceived monetary value of debt aversion. They found evidence of two sources of debt aversion, with debt aversion mostly being attributable to labeling effects. Using an experimental survey with treatment scenarios to test attribute frames of a gain, loss, or aspiration, Bartholomae, Kiss, Jurgenson, Worthy, Kim, and O'Neill examined gender differences in attitudes toward student loan debt. They found no gender differences in attitude toward whether it is wise to borrow student loans to obtain a degree and the experimental treatment scenarios.

Taken together, the nine papers in this special issue provide a snapshot of the increased role of student loans and advance our insight into family and economic issues surrounding student loan debt. It is evident that this line of research will continue to be an important area of inquiry for the foreseeable future. I am most appreciative to the many reviewers who offered essential contributions to the review process and supported authors in their work. A special thanks and best wishes to Elizabeth Dolan, who enthusiastically embraced the notion of a special issue on student loans. As she steps down from her role as Editor-in-Chief, those of us working closely with her will miss her support and guidance.

Publisher's Note Springer Nature remains neutral with regard to jurisdictional claims in published maps and institutional affiliations.

Suzanne Bartholomae is an Assistant Professor and Extension State Specialist in the Department of Human Development and Family Studies at Iowa State University. Her research projects examine financial health, financial literacy, financial behaviors, and the efficacy of financial education interventions. She earned her PhD in Human Development and Family Science from The Ohio State University. She has recently been appointed as Associate Editor of JFEI. 